Proceedings

\title{
Analysis of Cloud Computing Usage on Performance: The Case of Turkish SMEs ${ }^{\dagger}$
}

\author{
Uğur Tevfik Kaplancalı 1,* and Murat Akyol ${ }^{2}$ \\ 1 Department of Management Information Systems, Yeditepe University, Istanbul 34755, Turkey \\ 2 A\&T Bank, Istanbul 34367, Turkey; Muratakyol1182@gmail.com \\ * Correspondence: ugur.kaplancali@yeditepe.edu.tr; Tel.: +90-216-578-1743 \\ + Presented at the 7th International Management Information Systems Conference, Online, \\ 9-11 December 2020.
}

Citation: Kaplancalı, U.T.; Akyol, M. Analysis of Cloud Computing Usage on Performance: The Case of Turkish SMEs. Proceedings 2021, 74, 11. https://doi.org/10.3390/proceedings 2021074011

Published: 4 March 2021

Publisher's Note: MDPI stays neutral with regard to jurisdictional claims in published maps and institutional affiliations.

Copyright: (c) 2021 by the authors. Licensee MDPI, Basel, Switzerland. This article is an open access article distributed under the terms and conditions of the Creative Commons Attribution (CC BY) license (http://creativecommons.org/licenses /by/4.0/).

\begin{abstract}
Small and mid-size enterprises (SME) are considered the backbone of developing economies in terms of reducing poverty and unemployment. Although most SMEs are still reluctant in new technology adoption, such as cloud computing, some benefited from the services provided by cloud technology. This study aims to assess the performance evaluation of small and mid-sized enterprises (SMEs) regarding the usage of cloud computing in their activities. The quantitative study was conducted on a sample of 112 respondents employed in Turkish SMEs. A research model is utilized based on performance specific scales. Results signified cloud technology's positive impact on business performance.
\end{abstract}

Keywords: cloud computing technology; business performance; SMEs; cloud migration

\section{Introduction}

Today, individuals and institutions have a tendency to maintain their needs independently from time and place. Especially in our decade, the concept of speed with technological developments has gained an important dimension. Therefore, technological developments are focused on services such as data processing and transmission speed. When it comes to data processing and transfer concepts, the most important technology is cloud computing [1]. Gartner forecasted that the public cloud services market would grow 21 percent in 2018, up from $\$ 145.3$ billion in 2017 [2].

The cloud computing concept can be defined as an inventory storage platform. Individuals or institutions may download their data from online inventory repositories onto their devices they use, without any preliminary preparation. In the same way, they may equip all their devices with the requirements that they demanded by synchronizing them. Therefore, the concept of "Cloud Computing" is not a product but rather a service. This service, which provides transaction and data transfer speed to individuals and institutions, is bundled within a system that combines network elements, many servers, huge amount of storage space, and different applications [3]. In general, cloud computing is a model for enabling ubiquitous, convenient, on-demand network access to a shared pool of configurable computing resources [4].

Corporations endeavor to reduce computing costs, and accordingly they started to integrate their IT operations and to use virtualization technologies. New cloud computing technologies helped corporations regarding the accomplishment of this situation. Cloud computing means a new level of information technology (IT) for corporations, and besides faster development cycles, it enables them to further reduce IT infrastructure and administration costs [5]. Over the years, Cloud Computing Technology (CCT) has emerged as a valuable way to embrace business benefits through improved internal efficiencies [6]. Studies in different countries revealed that perceived benefits of using 
cloud technology and services are evident in the case of small and mid-size enterprises (SMEs) $[7,8]$.

This study is about the examination of the effects of the cloud computing on general and business performance of Turkish SMEs. Past experience noted that SMEs experienced a gradual reception towards new technologies like cloud computing [9] as they find it challenging to invest in planning, managing and implementing complex computing technologies and services [10]. Considering technological factors are not the only significant factor in transition to CCT, emerging literature mostly focused on determinants of cloud computing adoption [11-13]. Yet the attention was on the migration and use of CCTs in developed countries with the influence of CCTs on business performance in developing countries receiving limited scholarly considerations. To tackle this apparent gap, a total of nine research questions were developed to analyze cloud technology use of SMEs in Turkey but only three of them are presented below because of the format limitations.

\section{Cloud Migration of SMEs}

Cloud services offer hardware and infrastructure services that can take shape in accordance with the required demands beside the flexible options they extend to corporations. The flexibility aspect provides institutions with advantages both in finances and time. However, along with all these offered advantages, concerns such as the quality of service or performance have grown gradually over time. However, the concerns of the institutions abstaining in the transition to cloud services have disappeared in many respects today with the exception of safety and performance remaining as the most prominent topics. The researchers divided the problems experienced in the transition to the cloud services as follows [14]:

- Internal factors include the slowing of the transition process due to the concerns of the institutions due to their own culture.

- External factors include the disruptions that may arise due to the risks inherent in cloud services or disruptions in service quality.

The institutions can understand the different control elements and security reasons brought by the IT functions in the form of an inverse or threatening element of the corporate culture they adopt. For this reason, micro enterprises can overcome the transition process to cloud cognition quickly and large enterprises with a corporate culture can survive the transition process more slowly and painfully [15] (p.182).

Institutions that consider the integration of modern structuring, such as cloud services, to their institutions as a risk also have difficulties in the adaptation process. Such institutions should review the advantages of traditional structures and cloud computing and formulate adaptation process strategies from a common point of view. Institutions should identify all the factors they see as a risk in the transition to cloud services, and review how cloud services can reduce these risks. They should get an advantageous position in a modern competitive environment by keeping their structures flexible by moving away from the rigid attitude of the traditional structure [16] (p. 1)

The starting point of these strategies is the process of obtaining information and research about cloud services. The success of the strategy to be determined depends on the fact that the cloud services are well known by the institutions. The next step is how to use the cloud services and what the advantages are. Companies aware of the cloud services should create their own expectations in line with this awareness. The next step is to test the integration process with pilot applications. Problems should be eliminated and service quality should be improved in line with the expectations of the institutions. Cloud services also offer the advantage of personalizing the institutions with the flexible structure that can be developed specifically for the institutions it provides for [17] (pp. 52$54)$. 
The process of transition to the cloud system is notable for its complex and demanding adaptation processes regarding SMEs. However, the transition of SMEs to cloud computing is easier than large-scale enterprises. For SMEs who wish to establish their own infrastructure, the IT field can be financially challenging and it may require a long period of time to get their IT backed-up. However, through CCT, SMEs receive the services they want in a short period of time and disadvantageous conditions such as preinvestment are eliminated [18] (pp. 145-146).

According to the results of the interviews conducted within the purview of micro and medium enterprises, the primary important demand of small enterprises is to prevent the expansion of data center departments during selection of cloud computing services (CCS) [13]. SMEs are also hesitant to adopt CCS managed by third parties since additional risk-level challenges occur, including privacy [19]. Some other factors affecting cloud computing adoption are "low awareness of the benefits of technology, limited budget allocation and technical know-how, poor infrastructure and hesitation about migrating to new technologies" [20] (p. 190). However, CCT and CCS transition numbers of SMEs are growing steadily and a recent survey revealed that SMEs' planned cloud usage due to COVID-19 was slightly higher for 37\% of respondents, whereas another $13 \%$ reported significantly higher cloud use [21].

\section{Research Model and Method}

This investigation has the objective of determining the influence of cloud computing on the organizational results, mainly the general performance. A pioneering study conducted in 1984 by Pulley and Braunstein established a linkage between the use of IT and organizational performance [22]. Later attempts to present a more integrated view of the IT contribution to the organizational results revealed positive effects. In search of direct evidence that IT has improved organizational performance, DeLone and McLean introduced a comprehensive taxonomy within a framework in 1992 [23]. DeLone and McLean's (D\&M) taxonomy posits six major dimensions or categories of IT success and these are: system quality, information quality, use, user satisfaction, individual impact, and organizational impact. The D\&M model was both criticized and adapted by many researchers and a recent study of SME's in Mexico utilized their framework after minor changes in variables; by adding the "quality of service" category only [24].

Former research has shown that quality dimensions of the IS are a distinctive characteristic of the perception of the user in the use of new technologies, thus a proven positive impact on performance is achieved. However, this study proposes variables or dimensions that are not related to the quality, because the cloud computing services are relatively new for Turkish SMEs and also it is assumed that available cloud computing applications or platforms have a proven record and market share. In this scope, our model focuses more on the characteristics of the user (assessor), corporation, systems used and adoption of cloud computing.

A descriptive scanning model, which is one of the quantitative research methods, was used. A descriptive scanning model is known as that which attempts to describe a phenomenon or situation in its previous or current state, and any interventions were not made to the case or event [25]. Accordingly, the research model shows that the differentiation situations of the general performance of the corporation by evaluating the use of a cloud information system and the perceptions of the evaluators of the companies using the cloud information system on the performance of the company after the installation of the information and the opinions of the enterprise regarding the performance of the information technologies are indicated in the research model (Figure $1)$. 


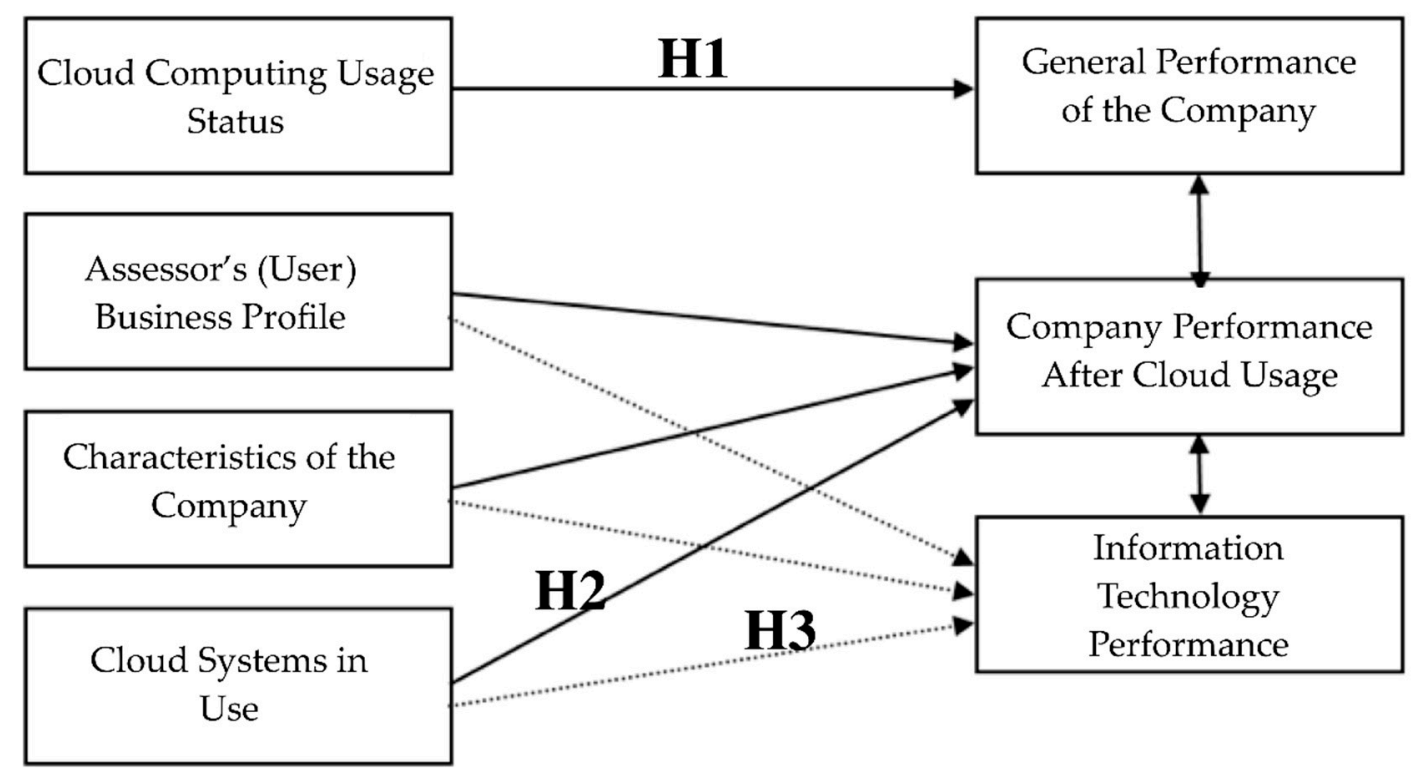

Figure 1. Research model.

As part of a broader study and based on the above research model along with scales introduced below, a total of nine hypotheses were tested to analyze the relationship between company performance and CCT use in addition to the perception of information technology in SMEs. Because of space limitations, three out of nine hypotheses are considered here:

Hypothesis 1 (H1). The overall performance of corporations differs in accordance with their cloud computing system usage.

Hypothesis 2 (H2). Corporations' performance after using cloud computing differs in accordance with their cloud computing system type.

Hypothesis 3 (H3). The information technology perception of the corporation differs in accordance with their cloud computing system type.

The SPSS 20 program was used during the evaluation of the data obtained for quantitative analysis. Distributions regarding characteristics of employees and their corporations have been shown as frequency and percentage. The control of the distribution structure, whether it is normal or not, was ensured by evaluating the coefficient values of skewness and kurtosis. Skewness and kurtosis coefficients can be valued range from $-\infty$ to $+\infty$. According to some research, these values have a normal distribution in the case in which they have values that range from -2 to +2 or from -3 to +3 [26]. In our research, it is concluded that the scores obtained from the performance scales had a normal distribution, and T-test and one-way analysis of variance from parametric tests for independent samples were performed. Tukey post hoc test was used for the determination of differentiating groups, which have meaningful value inferred from one-way analysis of test results. The findings obtained within the scope of this research were evaluated with a $95 \%$ confidence interval.

\subsection{Universe and Sampling of the Research}

The research universe consists of employees in various positions in the SMEs, which use or do not use cloud computing systems, and exist in service, manufacturing, export/import and other sectors. A sampling method was utilized in order to test the 
hypothesis of this research. A total of 112 personnel, who actively work in the corporations existing in various sectors, were selected as the sample of the research. For determination of the sample volume to be used, a purposeful sampling method was used. In a purposeful sampling method, the data collection period is completed when the required sample size is reached after interviewing the subgroup that represents the universe [27].

According to the calculation method of Yazıcıoğlu and Erdoğan (2004) regarding the sampling volume, it is attained that the required sample size should be 96 or more in the case of acceptance $p=0.5$ and $q=0.5,0.10 \pm$ sample error and $\alpha=0.05$ confidence interval [28]. A total of 112 employees, as the participants of this research, received the survey.

\subsection{Data Collection Methods}

The questionnaires were sent to the employees of the corporations via electronic mail and their responses were provided electronically in a similar fashion. The questionnaire consists of five sections, and data collection tools in the questionnaire are shown below:

1. Specifications of Assessors and Corporations Form

2. General Corporation Performance Scale

3. Sense and Features Form regarding Cloud Computing System

4. Corporation Performance Scale after using Cloud Computing

5. Information Technologies Performance Scale

In Assessors' and Corporations' Features Form, five questions were given to gain information regarding positions, divisions and their working time of the workers who participated in the research, and the corporations' sector and the number of staff.

General Corporation Performance Scale was excerpted from a 2008 research based on information systems performance of SMEs [29]. The scale consists of five expressions, and the evaluations are arranged as a single factor with a five-point Likert. The scale was evaluated as "Greatly agree (4.20-5.00)", "Agree (3.40-4.19)", "Neither agree nor disagree (2.60-3.39)", “Disagree (1.80-2.59)", “Greatly disagree (1.00-1.79)". Scale items determine the perception regarding the corporations' last three years profits, sales volume growth, position against their rivals, and financial performance changes. Cronbach's Alpha coefficient was determined as 0.90 in the former study. In our research, the mentioned coefficient was determined as 0.86 .

In Sense and Features regarding Cloud Computing System Form, five questions were used to gain information regarding cloud computing system usage status of corporations, which cloud computing system they use, its advantages and disadvantages, and their cloud computing application preference.

Corporation Performance Scale after using Cloud Computing, validity and reliability of the expressions collected by literature review were done in the Güvener's 2016 study regarding the performance of the corporations that use cloud computing systems as well as the ones that have not been using it yet [30]. The scale consists of eight questions. The scale consists of five expressions, and the evaluations are arranged as a single factor with a five-point Likert. The scale was evaluated as "Greatly agree (4.20-5.00)", "Agree (3.404.19)", “Neither agree nor disagree (2.60-3.39)”, “Disagree (1.80-2.59)”, “Greatly disagree $(1.00-1.79)^{\prime \prime}$. In the previous study, Cronbach's Alpha coefficient was presented as 0.927. In our research, the mentioned coefficient was determined as 0.77 .

Performance Scale of Information Technology was excerpted from the same 2008 research referred above for the general corporation performance scale [29]. The scale consists of five expressions, and the evaluations are arranged as a single factor with a fivepoint Likert. The scale was evaluated as "Greatly agree (4.20-5.00)", "Agree (3.40-4.19)", "Neither agree nor disagree (2.60-3.39)", "Disagree (1.80-2.59)", "Greatly disagree (1.001.79)". The scale includes statements regarding the corporations' perception of the information technologies' approaches, competitiveness, profitability and performance changes. In the former 2008 study, the Cronbach's Alpha coefficient was presented as 0.90. In our research, the mentioned coefficient was determined as 0.71 . 
In the control of the internal consistency of the scales, the Cronbach's Alpha coefficient was used. The Cronbach's Alpha confidence level was evaluated with the below-mentioned reference intervals [31]:

If $0.00 \leq \alpha<0.40$, then the scale is not reliable.

If $0.40 \leq \alpha<0.60$, then the scale is low reliable.

If $0.60 \leq \alpha<0.80$, then the scale is relatively reliable.

If $0.80 \leq \alpha<1.00$, then the scale is greatly reliable.

\section{Findings}

When the distribution of participants that were employed in the corporations was examined in accordance with their positions, $25.9 \%$ specialist, $23.2 \%$ engineer, $23.2 \%$ executive managers, $14.3 \%$ representative/in charge and $13.4 \%$ manager/director were in the positions of the corporations. The distribution of corporations in which participants work in accordance with their sector showed that 33\% operated in the services sector, $14.3 \%$ are export/import oriented, $13.4 \%$ manufacturing and $39 \%$ fell into other sectors.

When the distribution of corporations in which participants work was examined in accordance with their personnel number, $52.7 \%$ as less than $50,23.2 \%$ as between $51-250$, $24.1 \%$ as more than 251 were determined. Also, it has been determined that $63.4 \%$ of corporations were using a cloud computing system and $36.6 \%$ of corporations were not. Respondents who participated in the research from the corporations that have a cloud computing system stated disadvantages of the cloud computing system as $22.8 \%$ security, $16 \%$ data privacy, $15.1 \%$ cloud computing audit, $14.2 \%$ dependency to service provider, $13.2 \%$ bandwidth, $9.6 \%$ uncertain data location, $9.1 \%$ service level agreement.

The differentiation status of the participants' points gained from the general performance scale regarding their cloud computing system usage status of the corporation is shown in Table 1.

Table 1. Diversification situations of participant's points gained from general performance scale with respect to cloud computing usage status of the corporation.

\begin{tabular}{cccccc}
\hline $\begin{array}{c}\text { Cloud Computing } \\
\text { Usage Status of } \\
\text { Corporation }\end{array}$ & N & Mean & SD & & $\begin{array}{c}\text { General } \\
\text { Performance }\end{array}$ \\
\hline YES & 71 & 3.23 & 0.58 & $\mathrm{t}$ & 5405 \\
NO & 41 & 2.55 & 0.72 & $\mathrm{p}$ & 0000 \\
\hline
\end{tabular}

A statistically meaningful difference has been found with $95 \%$ confidence level $(\mathrm{t}=$ 5.405, $p<0.05)$ after t-test independent samples. This test was performed in order to examine the differentiation status of the participants in accordance with the cloud computing system usage status of the corporations' points which were gained from the participants' general corporation performance scale. According to this, the general performance of the corporations that used a cloud computing system $(X=3.23)$ has been found higher than those that did not use one $(X=2.55)$. These results validate our first research question.

The differentiation status of the participants' points gained from the corporation performance scale after cloud computing system usage with respect to cloud computing service application of the corporations is shown in Table 2. Cloud applications/platforms included in the questionnaire were selected based on the products with considerable market share and also availability in the country. Since it is not possible to list all applications or platforms offered in the market, and analysis based on types of applications or platforms is not the scope of this research, respondents were also provided with the "Other" option. 
Table 2. Diversification situations of participants' points gained from corporation performance scale after cloud computing system usage with respect to cloud computing service application being used by the corporation.

\begin{tabular}{cccccc}
\hline $\begin{array}{c}\text { Cloud Computing } \\
\text { System Being Used } \\
\text { by Corporations }\end{array}$ & N & Mean & SD & & $\begin{array}{c}\text { Corporation } \\
\text { Performance after } \\
\text { Using Cloud } \\
\text { Computing }\end{array}$ \\
\hline $\begin{array}{c}\text { iTubes } \\
\text { match/iCloud * }\end{array}$ & 8 & - & - & & \\
$\quad$ Dropbox & 10 & 3.57 & 0.57 & F & 5.788 \\
Amazon Cloud & 3 & - & - & P & 0.000 \\
$\quad$ Drive * & 23 & 3.71 & 0.39 & Levene & 0.385 \\
Google Drive & 16 & 3.77 & 0.53 & Diff. & $4-1$ \\
IBM Smart Cloud & 11 & 3.02 & 0.38 & & $4-2$ \\
Other & 11 & & & $4-3$ \\
\hline
\end{tabular}

* They have not been included into the analysis due to insufficient sample size. $(\mathrm{n}<10)$.

A statistically meaningful difference has been found with a 95\% confidence level ( $\mathrm{F}$ $=5.788, p<0.05$ ) after one-way analysis of variance (ANOVA), which was performed in order to examine the differentiation status in accordance with the cloud computing system usage of the corporations' points gained from participants' corporation performance scale after cloud computing system usage scale. According to the Tukey (Levene, $p>0.05$ ) post hoc test, which was performed to determine the groups' differentiation of the points gained from the scale, it has been found that the corporations' points $(X=3.02)$ of the corporation performance after cloud computing system, which has something other than a cloud computing system, were lower than others. These results validate the second research question, making it statistically significant.

The differentiation status of the participants' points gained from the information technologies performance scale with respect to cloud computing applications of their corporations is shown in Table 3. Cloud computing systems included in the below table are exactly the same as the applications or platforms used in testing our second hypothesis.

Table 3. Diversification situations in points gained from information technologies performance scale by participants who use a cloud computing system in their corporations with respect to their cloud computing application.

\begin{tabular}{cccccc}
\hline $\begin{array}{c}\text { Cloud Computing } \\
\text { System Being Used } \\
\text { by Corporations }\end{array}$ & N & Mean & SD & & $\begin{array}{c}\text { Information } \\
\text { Technologies } \\
\text { Performance }\end{array}$ \\
\hline $\begin{array}{c}\text { iTubes } \\
\text { match/iCloud * }\end{array}$ & 8 & - & - & & \\
$\quad \begin{array}{c}\text { Dropbox } \\
\text { Amazon Cloud }\end{array}$ & 10 & 3.70 & 0.44 & F & 3.867 \\
$\quad$ Drive * & 3 & - & - & P & 0.002 \\
Google Drive & 23 & 3.69 & 0.42 & Levene & 0.924 \\
IBM Smart Cloud & 16 & 3.52 & 0.53 & Diff. & $4-1$ \\
Other & 11 & 3.15 & 0.41 & & $4-2$ \\
\hline
\end{tabular}

* They have not been included into the analysis due to insufficient sample size. $(\mathrm{n}<10)$. 
Statistical meaningful difference has been found with a 95\% confidence level ( $\mathrm{F}=$ $3.867, p<0.05$ ) after one-way analysis of variance (ANOVA), which was performed in order to examine the differentiation status in accordance with cloud computing system usage of the corporations' points gained from participants' Information Technologies Scale. According to the Tukey (Levene, $p>0.05$ ) post hoc test, which was performed to determine the groups' differentiation of the points gained from the scale, it has been found that the corporations' points $(X=3.02)$ of the Information Technologies Performance that have something other than a cloud computing system mentioned in this research were lower than those that have the ones in this research. These statistically significant results validated our third and final research question.

\section{Conclusions}

Businesses of all sizes choose CCT with the expectation of new returns. These returns may be in different forms, such as minimized in-house IT spending or even some business gains resulting from improved data storage and processing capability. Cloud services provide various usage areas according to different profiles formed by supply and demand. However, CCT poses additional challenges for companies as existing infrastructure and privacy issues make implementations even more complex, especially for SMEs. Yet, more SMEs are now sure of the benefits and adopting cloud computing technology and services. This study targeted SMEs in Turkey and the results were encouraging.

Participants who had a cloud computing system in their companies have emphasized that a cloud computing system provided business agility $(21.9 \%)$ and efficient resource management $(21.1 \%)$ as advantages, and security $(22.8 \%)$ and data privacy $(16 \%)$ as disadvantages. Assessors emphasized that they used the cloud computing system in email and collaboration (29.3\%), and Finance-HR (24.7\%). Moreover, corporations that use a cloud computing system preferred the Google Drive system as $32.4 \%$.

It has been found that the general business performances of the SMEs that participated in the research have been diversified with respect to their cloud computing system usage. According to this, the general performances of the companies that use a cloud computing system were higher than those that do not. Furthermore, it has been determined that the companies' performance after the cloud computing system was diversified in accordance with their cloud computing systems, and lower performance change was observed for the systems except for Dropbox, Google Drive and IBM Smart Cloud. Similarly, findings from the information technology performance evaluations of the participants that use a cloud computing system show that business performance after using a cloud computing system was diversified in accordance with their cloud computing systems, and higher performance change was observed for the systems in use such as Dropbox, Google Drive and IBM Smart Cloud.

Our study empirically tested the perception for cloud computing in Turkish SMEs through two important items, general business performance and information technology used. Results revealed that the impact of CCTs was positive, so more incentives for SMEs to adopt cloud computing technologies can be thought of at the national IT policy level. The role of new technologies has become more meaningful for SMEs in developing countries as these technologies provide the necessary means to cope with less favorable periods and level the playing field for competing globally.

Cloud computing service quality and the level of cloud usage can be taken into consideration in future attempts investigating IT influence on performance. Moreover, the data were collected just before the COVID-19 pandemic lockdown in Turkey. Economic conditions worsened for the SMEs during lockdown but the use of IT and Internet multiplied as most people were telecommuting. Such conditions might have encouraged SMEs to migrate to cloud computing, therefore causing a significant change in cloud system usage. If such high cloud adoption is realized, developing new performance 
frameworks and CCT assessment models is crucial because the research model tested in this study is just a stepping stone, laid out prior to the coronavirus breakout.

Author Contributions: U.T.K. and M.A. conceived and designed the study; M.A. collected data and processed them; U.T.K. wrote the paper. All authors have read and agreed to the published version of the manuscript.

Funding: This research received no external funding.

Institutional Review Board Statement: Not applicable.

Informed Consent Statement: Not applicable.

Data Availability Statement: Data supporting reported results can be accessed through Thesis Central database of Higher Education Board (Turkey). Datasets are from Murat Akyol's thesis archieved by the number 635564 .

Conflicts of Interest: The authors declare no conflict of interest.

\section{References}

1. Sarıtaș, M.T.; Üner, N. Innovative Technologies in Education: Cloud Computing. J. Res. Educ. Teach. 2013, 3, 180-189.

2. Gartner. Available online (https://www.gartner.com/en/newsroom/press-releases/2018-09-12-gartner-forecasts-worldwidepublic-cloud-revenue-to-grow-17-percent-in-2019 (accessed on 11 June 2020).

3. Mell, P.; Grance, T. The NIST Definition of Cloud Computing. Natl. Inst. Stand. Technol. Spec. Publ. 2011, 800-145, 1-3.

4. National Institute of Standards and Technology (NIST). Available online (https://www.nist.gov/newsevents/news/2011/10/final-version-nist-cloud-computing-definition-published) (accessed on 24 December 2019).

5. Boss, G.; Malladi, P.; Quan, D.; Legregni, L.; Hall, H. Cloud Computing; IBM Corporation: New York, NY, USA, 2007.

6. Folinas, D.; Manijas, I.; Graham, D. E-Logistics and E-Supply Chain Management: Applications for Evolving Business, 1st ed.; IGI Global: Hershey, PA, USA, 2013; ISBN 9781466639140.

7. Vasiljeva, T.; Shaikhulina, S.; Kreslins, K. Cloud Computing: Business Perspectives, Benefits and Challenges for Small and Medium Enterprises (Case of Latvia). Procedia Eng. 2017, 178, 443-451.

8. Neicu, A.; Radu, A.; Zaman, G.; Stoica, I.; Florian, R. Cloud Computing Usage in SMEs. An Empirical Study Based on SMEs Employees Perceptions. Sustainability 2020, 12, 4960.

9. Yeboah-Boateng, E.O.; Essandoh, K.A. Factors influencing the adoption of cloud computing by small and medium enterprises in developing economies. Int. J. Emerg. Sci. Eng. 2014, 2, 13-20.

10. Carroll, N.; Helfert, M.; Lynn, T. Towards the Development of a Cloud Service Capability Assessment Framework. In Continued Rise of the Cloud: Advances and Trends in Cloud Computing, 1st ed.; Mahmood, Z., Ed.; Springer: London, UK, 2014; pp: 289-336.

11. Gangwar, H.; Date, H.; Ramaswamy, R. Understanding determinants of cloud computing adoption using an integrated TAMTOE model. J. Enterp. Inf. Manag. 2015, 28, 107-130, doi:10.1108/JEIM-08-2013-0065.

12. El-Gazzar, R.; Hustad, E.; Olsen, D.H. Understanding cloud computing adoption issues: A Delphi study approach. J. Syst. Softw. 2016, 118, 64-84, doi:10.1016/j.jss.2016.04.061.

13. Khan, N.; Al-Yasiri, A. Framework for cloud computing adoption: A roadmap for SMEs to cloud migration. Int. J. Cloud Comput. Serv. Archit. 2015, 5, 1-15. Available online: Three-reasons-skeptics-arent-adopting-cloud (accessed on 12 May 2020).

14. Nebuloni, G. Accelerate Hybrid Cloud Success: Adjusting the IT Mindset, white paper, IDC, February 2011. Available online https://www.scribd.com/document/49812284/IDC-Accelerate-Hybrid-Cloud-Success-Adjusting-the-IT-Mindset (accessed on 8 March 2020

15. Marston, S.; Li, Z.; Bandyopadhyay, S.; Zhang, J.; Ghalsasi, A. Cloud Computing: The Business Perspective. Decis. Support Syst. 2011, 51, 176-189.

16. Şanl, O. Cloud Computing. In Academic Information Conferences; Anadolu University: Eskişehir, Turkey, 2011.

17. Wyld, D.C. Moving to the Cloud: An Introduction to Cloud Computing in Government. IBM Center for the Business of Government, 2009. E-Government Series. Available online http://www.businessofgovernment.org/report/moving-cloudintroduction-cloud-computing-government (accessed on 1 July 2020).

18. McKinsey \& Company. Innovation Project of Information Society Strategy: Information Technology Axis, Global Trend and Country Examination Report 2013; McKinsey \& Company: Hong Kong, China, 2013.

19. Hashizume, K.; Rosado, D.G.; Fernández-Medina, E.; Fernandez, E.B. An analysis of security issues for cloud computing. J. Internet Serv. Appl. 2013, 4, 5.

20. Thilini, C. Determinants of cloud computing adoption among SMEs in Sri Lanka: A meta theoretical framework. Int. J. Asian Soc. Sci. 2019, 9, 189-203.

21. Flexera. Available online: https://www.flexera.com/blog/industry-trends/trend-of-cloud-computing-2020/\#cloud-workloads (accessed on 11 July 2020).

22. Pulley, L.B.; Braunstein, Y.M. Scope and Scale Augmenting Technological Change: An Application in the Information Sector; Juswalla, M., Ebenfield, H., Eds.; Elsevier: Amsterdam, The Netherlands, 1984. 
23. DeLone, W.; McLean, E. Information systems success: The quest for the dependent variable. Inf. Syst. Res. 1992, 3, 61-95.

24. Almazán, D.A.; Tovar, Y.S.; Quintero, J.M.M. Influence of Information Systems on Organizational Results. Contaduría y Administración 2017, 62, 321-338.

25. Karasar, N. Scientific Research Method; Nobel Publishing: Ankara, Turkey, 2016.

26. Ak, B. Data Arrangement and Visualization. In SPSS Applied Multivariate Statistical Techniques, 4th ed.; Kalayc1, Ş., Ed.; Asil Publishing: Ankara, Turkey, 2009.

27. Gürbüz, S.; Şahin, F. Research Methods in Social Sciences; Seçkin Press: Ankara, Turkey, 2014.

28. Yazıcıoğlu, Y.; Erdoğan, S. SPSS Applied Scientific Research Methods; Detay Publishing: Ankara, Turkey, 2004; pp. 49-50.

29. Akdede, S.H.; Turan, A.H. The Effects of Information Systems on the Performance of SMEs: An Empirical Practice with Resource Based Approach in Denizli City. Ankara Univ. SBF Mag. 2008, 63, 1-28.

30. Güvener, T. Evaluation of Information Systems Being Used by Istanbul Companies in Terms of Value Chain Analysis and Project Management, and Usage of Cloud Computing Technology. Master's Thesis Beykent University, Social Sciences Institute, İstanbul, Turkey, 2016.

31. Özdamar, K. Statistical Data Analysis with Packaged Programs; Kaan Release Publish: Eskişehir, Turkey, 2004 ; p. 699. 